\title{
Why do so few low and middle-income children attend a grammar school? New evidence from the Millennium Cohort Study
}

Proponents argue that grammar schools enhance social mobility by allowing high-attaining pupils to attend elite schools, no matter what their social background. However, disadvantaged pupils cannot benefit from grammar schools unless they gain access to them. In this paper, we use rich cohort data to investigate the strength of, and reasons for, the socio-economic gradient in grammar school entrance rates. Presenting new evidence for England and Northern Ireland, we find stark differences in grammar school attendance by family income. Although differences in prior academic attainment can partly explain these gaps, parental school preferences and private tuition also play an important role. Entrance to grammar school therefore depends on birth and wealth, as well as academic attainment.

Key Words: Grammar schools, selective education, private tuition. 


\section{Introduction}

The 1944 Education Act established a selective school system in UK, in which pupils were sorted into different schools depending on academic attainment at age 11. The reform aimed to "create an aristocracy of intellect to replace the aristocracy of birth and wealth" (Norwood Report, 1943). The highest attaining pupils would be selected through the "Eleven Plus" test and offered an academically oriented education funded by the taxpayer. Grammars therefore reflected a post-war vision in which "the country's cleverest children from all classes would gain the opportunity to succeed upon their own merits" (SESC, 2018). Although the grammar system was abolished in large parts of the country during the 1960s and 1970s, around 160 selective grammar schools, educating approximately five percent of pupils, remain in England today. In Northern Ireland the grammar school system remains firmly in place. Moreover, in recent years selective schools have received renewed support, including from the Prime Minister Theresa May, who believes that expanding grammars will increase social mobility.

Whether grammar schools provide low and middle-income pupils with better life opportunities is however, open to debate. Indeed, a wide-ranging literature suggests that this may not be the case (Hanushek \& Woßmann, 2006; Burgess, Dickson, \& MacMillan, 2014; Burgess, Crawford, \& MacMillan, 2017). One reason is that not enough low and middle-income children gain entry to grammar schools in the first place. Just three percent of pupils educated in a grammar school in England are eligible for Free School Meals (FSM), despite accounting for 13 percent of the pupil population (Andrews, Hutchinson, \& Johnes, 2016). However, we currently know surprisingly little about why this is the case.

We investigate this question using data from the Millennium Cohort Study (MCS). The rich array of information on pupils in the MCS, who are now at secondary school, means we are able to consider, for the first time, a range of potentially important mediating factors driving this relationship. Are low and middle-income families less likely to apply to grammar schools? Do they differ in their school preferences, or aspirations? Or is it because they are less able to afford tutoring for the entrance test?

Our results highlight stark differences in grammar school entrance rates according to family income, which persist even after controlling for prior attainment. These socio-economic gaps in grammar attendance are accounted for in part by differences in parental preferences and in part by the use of private tutors. We conclude that grammar schools have failed to fulfil their meritocratic objectives of selecting and educating the highest attaining pupils from all classes. 


\section{Conceptual Framework: What mechanisms might drive the relationship between family income and grammar school attendance?}

\section{Prior attainment}

Entry to grammar schools requires pupils to sit a competitive examination. There are however, large disparities in academic attainment between socio-economic groups, visible as young as age 3 (Jerrim \& Vignoles, 2013). Hence by the time secondary-school choices are made, low and middle-income children will have significantly lower levels of academic attainment than their high-income peers. Indeed, lower-income families may reason that the chances of their offspring passing the entrance exam are likely to be low, and so therefore decide not to enter them for the test in the first place.

\section{$\underline{\text { Parental school preferences }}$}

Parents in England are able to express a preference for which school their child attends. Indeed, proposals to expand grammar schools can be seen as the latest development in the proliferation of different "school types" from which parents can choose (Gorard, 2012). High- and lowincome groups may place different emphasis on school attributes. For instance, economists have found that high-income families place a greater weight on schools with good results (Burgess, Greaves, Vignoles, \& Wilson, 2015; Hastings, Kane, \& Staiger, 2004). Sociologists of education have also long emphasised that working class and middle-class parents tend to value different characteristics of schools. For example, Gewirtz, Ball and Rowe (1994), Reay and Ball (1997) and Ball, Rowe and Gewirtz (1996) all emphasise the positive value placed on locality and community by working class parents. Alternatively, lower socio-economic groups may associate grammar schools with an academic elitism (Sutton Trust, 2013), with which they do not feel "at home" (Reay \& Ball, 1997).

\section{Location / distance}

Alternatively, lower and middle-income families may struggle to gain access due to issues of distance. Economists have shown that house prices tend to be noticeably higher in neighbourhoods surrounding higher quality schools (Gibbons \& Machin, 2008). Sociologists have also documented the ways in which middle-class families pursue strategic house moves in order to gain entry to their preferred school (Reay, 2004). Affluent families are better able to cope with the costs of bus passes or train tickets to enable their children having to commute to school in selective areas (Gewirtz et al., 1994).

\section{$\underline{\text { Parents and teachers recognition of academic potential }}$}


Low and middle-income parents are less likely to have attended grammar school themselves. Consequently, they may be less able to identify the potential of their high-attaining child or lack the cultural capital to navigate the school choice process (Ball \& Vincent, 1998). Similarly, teachers in primary schools with more disadvantaged intakes may have less experience in advising parents on the grammar admissions process. Indeed, qualitative research by the Sutton Trust has suggested that "some primary school teachers do not think that grammar schools are suitable for children from poorer families" and that some lower-income parents "might prefer a more 'rounded' education for their child" (Sutton Trust, 2013). Teachers low expectations for certain pupils may even be inadvertently discouraging working class pupils from applying, creating a self-fulfilling prophecy (Gazeley \& Dunne, 2007).

\section{$\underline{\text { Aspirations and expectations }}$}

Low and middle-income parents may have different aspirations for their offspring (Schoon \& Parsons, 2002; Sutton Trust, 2013). Grammar schools are seen as a route to university, which means that parents with high educational expectations may also push for their child to attend a selective school (Reay, 2004). Working class parents seem to be more likely to prioritise children's school preferences, while middle-class parents are more like to intervene to steer them towards schools that meet their competitive, aspirational expectations (Reay \& Ball, 1998; Francis et al., 2017). Working class parents may also avoid applying to academically elite schools in part because they wish to protect their children from the risk of failure (Reay \& Ball, 1994).

\section{Coaching / tutoring for the entrance examination}

A final way in which high-income families might use their resources to gain an advantage is by paying for private tutoring for the grammar school entrance exam. The tests typically involve a mathematics, English and non-verbal reasoning component, and include material that is not aligned with the national curriculum taught in English and Northern Irish schools. There are several companies offer services helping familiarise and prepare young people for this exam. These services are expensive and are likely disproportionately used by families with higher incomes (Ireson \& Rushforth, 2011).

\section{Data}

In order to provide some empirical evidence on the importance of these different channels, we use data from the Millennium Cohort Study (MCS), a rich, nationally representative longitudinal study of UK children. The MCS uses a stratified, clustered survey design (Plewis, 
2004). Six sweeps have been conducted between 2000 and 2015, when children were nine months, 3, 5, 7, 11 and 14 years old. Parents, children and their teachers have been interviewed within the various sweeps. Of the 18,819 cohort members who participated at nine months, 11,726 remained in the study at age 14 (7,739 in England and 1,115 in Northern Ireland). This reflects attrition rates of 34 percent in England and 43 percent in Northern Ireland respectively. We apply the MCS response weights throughout our analysis to adjust for non-random nonresponse.

\section{Defining 'selective education areas' in England}

Whereas Northern Ireland has a completely selective education system, the distribution of England's 163 grammar schools across the country is highly uneven. Ten of the 152 local education authorities (LEAs) in England are considered to be wholly selective ${ }^{1}$. However, children often cross over local boarders to attend these schools, meaning around a quarter of the grammar school intake actually live in a different LEA to their school (Allen, 2016). In addition, there are a number of 'isolated' grammar schools spread across England. Figure 1 illustrates this situation, with the left-hand panel highlighting the concentration of selective schools across England, and the right-hand panel the home location of pupils who attend such schools (Allen, 2016).

Figure 1 has implications for how we define 'selective education areas' in England. We follow two approaches. The first is to simply concentrate upon the ten fully selective LEAs only. This has the advantage of being a clean and clear definition but ignores children who travel across borders or live near one of the isolated grammar school, reducing our sample size in England to 675. Our second approach includes the ten selective LEAs plus any child who lives in a Middle Super Output Area (MSOA) where at least ten percent of children attended a grammar school over the last five years ${ }^{2}$. This definition is less clear but gives us a larger sample of 1,095 in England. The data include 1,220 MCS children who live in Northern Ireland. We report results following the first (less restrictive) definition in the main body of the paper, with Appendix $\mathrm{C}$ reporting alternative results using the second (more restrictive) definition.

\footnotetext{
${ }^{11}$ The 10 fully selective LEAs in England are Bexley, Buckinghamshire, Kent, Lincolnshire, Medway, Slough, Southend-on-Sea, Torbay, Trafford and Sutton.

${ }^{2}$ Middle Super Output Areas (MSOAs) are small geographic areas within England. The minimum population within an MSOA is 5,000 individuals, maximum of 15,000 individuals, with a mean of 7,200. In total, England can be divided into 6,781 separate MSOAs.
} 


\section{Private schooling}

An additional challenge is that high-income families may decide to send their child to a private independent school, particularly if they fail to pass the grammar school entrance test. This is not such a problem in Northern Ireland where the independent school sector is extremely small. It is, however, more of an issue in England, where around seven percent of the population attend a fee-paying school. We employ three approaches to deal with this. In our main results we exclude any child who attends a private secondary school from the analysis. In Appendix $\mathrm{D}$ we model the probability of attending either a grammar school or a private school. And in Appendix B we estimate a multi-nominal logistic regression model, with non-grammar state schools, grammar schools and independent schools as three separate groups. Most of our main results remain unchanged whichever approach is used.

\section{$\underline{\text { Measurement of family income }}$}

The MCS survey organisers use modified OECD scales to create a weekly equivalised income variable within each sweep. Where families refused to provide this information (typically $<10 \%$ of cases) the survey organisers have imputed this information (see Hansen, 2014). As is standard in related literature (see Blanden, Gregg, \& MacMillan, 2013), we create a long-run average household income measure by averaging the weekly equivalised income variable across the age nine months, three, five and seven-year survey rounds ${ }^{3}$. The mean of this weekly equivalised household income variable is $£ 396$ in England and $£ 292$ in Northern Ireland. In our analysis, we divide children into four family-income quartiles.

\section{Grammar school attendance}

In the age 14 sweep of the MCS, parents were asked to name their child's school. We use this information to define a binary variable taking a value one if they attend a grammar school and zero otherwise.

\section{$\underline{\text { Measures of cognitive skills }}$}

One of the key strengths of the MCS is that cohort members have completed a number of cognitive tests throughout childhood. In our models that control for prior attainment, we focus upon:

- Naming vocabulary (ages 3 and 5)

\footnotetext{
${ }^{3}$ We do not include the age 11 survey round data, as the income data seems to have been coded differently to the previous sweeps.
} 
- Pattern construction (ages 5 and 7)

- Picture similarities (age 5)

- Word reading (age 7)

Although the MCS also contains a number of cognitive assessments taken at age 11, and prior to grammar school entry, we view these as potentially endogenous - children's scores on these tests may have been affected by parental decisions to apply to grammar schools (e.g. via paying for extra tuition to increase their chances of passing the entrance test $)^{4}$. Hence we do not control for these in our primary analysis. However, in Appendix A we do present results from a robustness test, illustrating how our parameter estimates change if these additional attainment measures are also controlled.

\section{$\underline{\text { Parental school preferences }}$}

When their child was in the final year of primary school, parents were asked about their secondary school preferences. This included the question: "Which of these factors were important in choosing a secondary school?" (yes/no). They were asked about each of the following issues in turn, and then asked which they felt was the most important:

(a) Child wanted to go there;

(b) School is near to home;

(c) His/her friends intending to go there;

(d) His/her brother/sister goes there;

(e) Other relative goes there;

(f) Academic reputation;

(g) Strong discipline policy;

(h) Good extra-curricular activities;

(i) School has specialist curriculum;

(j) Good facilities;

(k) General good impression;

(1) Religious grounds.

\footnotetext{
${ }^{4}$ The additional attainment measures available at age 11 measure pupils' verbal similarities and spatial working memory, along with performance in the Key Stage 2 national examinations (England only).
} 
Within our analysis, we are therefore able to investigate how strongly the above are associated with parental income within selective education areas, and the extent that these parental school preferences mediate the relationship between income and grammar school attendance.

The measures parents take to get their child into a grammar school

In the age 11 survey, parents are also asked a series of questions about the steps they have taken to get their child into the school of their choice. Specifically, they were asked "which, if any, of the steps on this card did you take in order to help improve your child's chance of getting into a particular secondary school?":

(a) Moved home;

(b) Short-term renting;

(c) Used the address of a relative or friend;

(d) Got child into a particular primary school;

(e) Arranged extra tuition or coaching for child;

(f) Arranged for extra curricula activities for child (and in which subject);

(g) Joined a church or place of worship;

(h) Asked someone with influence in the process to recommend your child;

(i) Other steps

\section{$\underline{\text { Parental views on their children's behaviour and academic skills }}$}

Parents were also asked to report their views on various aspects of the cohort member's academic skills and behaviour. With regards the former, parents were asked if the child had difficulty at school in mathematics, reading and writing on a three-point scale (no difficulty, some difficulty and great difficulty). Likewise, parents also completed the Strengths and Difficulties Questionnaire (SDQ) on behalf of their child across a number of survey sweeps. This captures parental views on their child's non-cognitive skills and behavioural attributes. In our analysis, we use the age 7 measures of these variables.

\section{Primary school teacher's views on the child's behaviour and academic skills}

In the age 7 MCS sweep, primary school teachers were asked to rate the cohort members' academic attainment in eight areas, including speaking and listening, reading, writing, science and mathematics. This was done on a five-point scale, from well below average to well above average. They also completed the Strength and Difficulties Questionnaire (SDQ) reflecting their views on the child's behaviour and socio-emotional skills. 


\section{Methodology}

A set of sequential binary response models will be estimated separately for England and Northern Ireland, investigating the link between household income and grammar school entrance. These will attempt to 'explain' (in a statistical sense) why children from high-income families are more likely to attend a grammar school than their low and middle-income peers. Formally, this model is specified as:

$A_{i j}=\beta_{1} \cdot$ Inc $_{i}+\beta_{2} \cdot S_{i}+\beta_{3} \cdot$ Tutor $_{i}+\beta_{4} \cdot P_{i}+\beta_{5} \cdot V_{i}+\beta_{6} \cdot T_{i}+\beta_{7} \cdot E_{i}+G_{j}$

Where:

$A_{i j}=$ Whether cohort member $\mathrm{i}$ attends a grammar school $(0=$ no; $1=$ yes $)$.

$I n c_{i}=\mathrm{A}$ set of dummy variables referring to permanent family income quartile.

$S_{i}=$ Prior academic attainment of child i, as measured by the MCS tests up at age seven.

Tutor $_{i}=$ A vector of variables capturing the extent to which the child has received private tutoring.

$P_{i}=$ A vector of dummy variables capturing parental school preferences.

$V_{i}=$ Parental views on child i's cognitive and non-cognitive skills.

$T_{i}=$ Primary school teacher views on child i's cognitive and non-cognitive skills.

$E_{i}=$ Parental educational expectations for child $\mathrm{i}$.

$G_{j}=$ Geography fixed effects.

$\mathrm{i}=$ Cohort member $\mathrm{i}$.

$\mathrm{j}=$ Local area $\mathrm{j}$.

In all models, the complex MCS design (clustering, stratification and weighting) will be taken into account using the Stata survey ('svy') command (Ketende \& Jones, 2011). Multiple imputation using chained equations (MICE) has been used, where possible, to account for missing covariate data. For most covariates, the amount of missing data is modest (typically $<10 \%)$. One exception to this is the data from primary school teachers $\left(T_{i}\right)$ where around a third of observations are missing for Northern Ireland. 
This model will be built up sequentially, adding sets of control variables one at a time. Our key interest is in the parameter $\beta_{1}$ - how strong is the relationship between household income and grammar school entry, conditional upon the other factors included in the model. Although our outcome is binary, linear probability models (OLS regression) will be used when following this sequential modelling process. Our preference for estimating linear probability models over some potential alternatives (e.g. logit or probit models) is due to the known methodological problems with comparing logistic regression parameter estimates across nested models (Mood, 2010). Specifically, any change in parameter estimates could be owing to either 'confounding' or 'rescaling', with only the former of substantive interest. We also report logistic regression models in Appendix B to demonstrate the robustness of our results to this choice.

\section{Results}

\section{$\underline{\text { Northern Ireland }}$}

To begin, Figure 2a illustrates the bivariate relationship between permanent family income and grammar attendance in Northern Ireland. The association is positive and linear above the $25^{\text {th }}$ percentile. There is, for instance, around a 20 percent chance of all children below the $25^{\text {th }}$ percentile attending a grammar school. This probability then steadily increases, up to around 40 percent at the $50^{\text {th }}$ percentile and around 70 percent at the $90^{\text {th }}$ percentile.

\section{$<$ Figure $2>>$}

These results are formalised in model 1 (see Table 1), where the link between family income and grammar school attendance is estimated including just basic demographic controls. Compared to the lowest income quartile (reference group), young people's whose families are in the third income quartile are around 30 percentage points more likely to attend a grammar school. This increases to a 53 percentage point gap when one compares the top and bottom income quartiles.

\section{$<<$ Table 1 >}

To what extent is this result a reflection of differences in children's prior academic attainment between family income groups? Model 2 addresses this issue by adding a host of academic attainment controls up to when children are age 7 . The estimated income parameters fall almost by half, with the difference between children in the bottom two quartiles no longer statistically significant. Nevertheless, there continues to be a substantial socio-economic grammar school 
entrance gap, with those in the top income quartile still 33 percentage points more likely to attend a grammar school than their peers in the lowest income group.

The third model (M3) adds in additional controls for local area (electoral ward) fixed effects. Interestingly, the inclusion of these fixed effects helps to further explain some of the socioeconomic gap in grammar school entrance rates in Northern Ireland, particularly the difference between families in the top income quartile and the other income groups. Specifically, the estimated parameter for the top income quartile has fallen by a further eight percentage points (from 33 to 25 percentage points). A similar, though smaller, drop also occurs for the third quartile (18 to 15 percentage points). Our interpretation is that this suggests distance and local community factors (potentially including religion) is helping to exacerbate socio-economic inequalities in grammar school access in Northern Ireland. Even so, there remains large socioeconomic gaps in access to grammar schools.

What else, other than location and prior attainment, can explain this gap? Table 2 provides some descriptive evidence on the steps high-income parents take to get their child into their chosen school. The factor that comes shining through is private tuition, with high-income families much more likely to use tutoring/coaching to get their child into the school of their choice. Specifically, families are around six to seven percentage points more likely to report using private tutors as a method of gaining access to a particular school for each $£ 100$ increase in family income. Note that there is a significant seven percentage point increase in English and mathematics tuition per $£ 100$ increase in family income, but essentially no association in science. This is consistent with the content of grammar school entrance tests, which do not include science, but have a strong English and mathematics component.

\section{$<$ Table $2>>>$}

But does this tactic actually work? Table 2 panel (b) provides some descriptive evidence on this point, illustrating the unconditional association between receiving coaching/tuition and grammar school entrance rates. It illustrates how almost 80 percent of children in Northern Ireland who received coaching/tuition for the entrance test gained entry to a grammar school, compared to just 40 percent of those who did not receive any coaching/tuition. This result continues to hold even when we enter these private tuition variables into our grammar school access model (Model 4 in Table 1), which conditions upon prior attainment and local area characteristics. Specifically, parents who said that they used coaching to get their offspring into their chosen school, and who paid for private maths and English tuition, were around 18 
percentage points more likely to get their child into a Northern Irish grammar school (conditional upon the host of other variables already included in the model) ${ }^{5}$. As high-income families are disproportionately likely to pay for private tutors, the income parameter estimates in Table 1 fall between Model 3 and Model 4; from around 25 percentage points down to around 22 percentage points with respect to the highest income group.

\section{$<<$ Table $3>>$}

The next factor we add into our grammar school entrance model is parental school preferences. As can be seen from Table 3, Parental income has a strong and significant association with a number of school preferences. Two of the most notable are good examination results and a general good impression of the school. Specifically, in Northern Ireland, each $£ 100$ increase in weekly income leads parents to express a nine percentage point increase in good school examination results and a five percentage point increase in good impression of the school.

When we add these variables capturing parental school preferences to our model, the income parameter estimates drop again, with parental school preferences having roughly the same association as the variables capturing private tuition. For instance, the difference between the top and bottom income groups in Table 1 has fallen by a further four percentage points between Model 4 and Model 5 (which includes parental school preferences for a school with good grades as the only additional control). Interestingly, no further change in the income parameter estimates occurs between Model 5 and Model 6, when the full range of parental school preference variables (as reported in Table 3 ) are also added into the model.

The next two models include additional controls for parents' (Model 7) and teachers' (Model 8) views of their child's cognitive and non-cognitive skills. The high-income parameter estimate falls from 18.2 percentage points in Model 6 to around 14.5 percentage points in Model 8. The final model (Model 9) additionally includes a control for parental educational expectations for the child; a factor which previous qualitative work has suggested may help to explain socio-economic differences in grammar school attendance rates (Sutton Trust 2013). In Northern Ireland, we find no evidence that this is the case, with the family income parameter estimates in Table 1 hardly change between Model 8 and Model 9. Around a third of the raw household income gap in grammar school entrance rates remains unexplained.

\footnotetext{
5 These results are not formally reported, but the joint impact of the private tutoring variables included in the model are statistically significant. The full set of parameter estimates are available from the authors upon request.
} 


\section{$\underline{\text { England }}$}

In Table 4 we present results from our grammar school access model for England, analogous to the Northern Irish results presented in Table 1. This is accompanied by Figure $2 b$, which illustrates the unconditional relationship between family income percentile and the probability of attending a grammar school in England.

\section{$<$ Table 4 >>}

The first notable feature of these results is that the family income gradient in grammar school attendance is not as steep in selective areas of England as in Northern Ireland. For instance, the raw (unconditional) gap between the high- and low-income groups is around 35 percentage points in England, compared to more than 50 percentage points in Northern Ireland. We put this difference down to the different structure of the education system in these two countries. Specifically, failure to gain entry to a grammar school in Northern Ireland means that children will enter the equivalent of 'secondary modern' (i.e. a school track designed specifically for lower academic achievers, with greater proportions of children from lower socio-economic backgrounds). The same is not true in England due to (a) the opportunity to travel across local education authority borders to attend a comprehensive school and (b) the presence of a more extensive independent (private) school sector ${ }^{6}$. Consequently, high-income parents in England have more alternative school options available than parents in Northern Ireland.

Returning to estimates from the grammar school access model for England presented in Table 4, a number of consistent findings with the Northern Irish results emerge. For instance, note how prior academic attainment explains a substantial proportion of the grammar school access gap between high and low-income children. Specifically, the high-income parameter estimate falls by just over one-third, from around 36 percentage points in Model 1 to around 21 percentage points in Model 2, once prior attainment controls through to age 7 are included. Nevertheless, as in Northern Ireland, substantial differences between income groups remain even conditional upon children's prior attainment.

Although the inclusion of local education authority fixed effects in Model 3 does little to change our results, we do find evidence that private tutoring and coaching for school entrance

\footnotetext{
${ }^{6}$ Recall that we have excluded children who go on to attend a private secondary school in England. We have created an alternative version of Figure 2 for England where we illustrate the link between family income and the probability of attending either a private or independent school. The income gradient then becomes somewhat steeper in England. This alternative graph is available from the authors upon request.
} 
test plays a pivotal role in explaining socio-economic differences in grammar school attendance. Table 5 presents descriptive evidence on this issue, with panel (a) illustrating how every $£ 100$ in weekly equivalised household income is associated with a six percentage point increase in the probability that the child receives coaching for the entrance test, and an extra four to five percentage point increase in private maths and English tuition. Again, the same is not true for tutoring in science, which is not part of the grammar school entrance test. The relationship between family income and private tuition is also a lot shallower in comprehensive areas than in selective areas in England. This is complemented by Table 5b, which shows that almost three-quarters of children living in a selective area who were coached to pass the test gained entry, compared to only 14 percent of those who were not coached. Together, these factors combine to drive a large decline in the high-income parameter estimate between Model 3 and Model 4. Specifically, the difference between high and low income pupils in grammar school entrance rates falls from around 24 to 13 percentage points after private tuition has been taken into account ${ }^{7}$. This is larger reduction in the high-income parameter estimates than in Northern Ireland.

Table 6 provides further information by illustrating differences in the probability of receiving: (a) coaching for the entrance test; (b) tutoring in mathematics and (c) tutoring in English amongst children living in selective education areas. It highlights a number of important results. First, as already discussed, children from high-income backgrounds are more likely to receive all forms of coaching/tutoring than children from low income backgrounds. For instance, around 16 percent of children in the bottom family income quartile received tuition in mathematics compared to 34 percent of those in the top income quartile. When we explore differences by prior achievement (measured at age 7), we only observe a substantial gradient for response to the question asking about coaching and not about mathematics and English tuition. For instance, less than five percent of children in the bottom reading achievement quartile reported receiving coaching to get into their selected school, compared to 29 percent of those in the top quartile. By contrast, the gradient for tutoring in English and mathematics is less clear. If anything, it is actually lower achievers that receive this form of support. Consequently, it seems that while higher achievers are more likely to get coaching on the

\footnotetext{
${ }^{7}$ Note that the full set of parameter estimates from model 4 illustrates how children who receive coaching for the entrance test and private tutoring in English and mathematics are around 50 percentage points more likely to attend grammar school than those who do not. In other words, the key finding from Table $5 \mathrm{~b}$ continue to hold, even after prior attainment, local education area and family background factors have been controlled.
} 
entrance test, it is lower achievers who are more likely to receive extra tuition in English and mathematics.

Beyond this point, the inclusion of additional controls does relatively little to further reduce the household income parameter estimates ${ }^{8}$. Table 7 , for instance, illustrates how most parental school preferences in selective education areas in England do not vary substantially with household income (with the exception of good exam results and general impressions of the school). Consequently, their inclusions within Models 5 and 6 do relatively little to change our results. Likewise, the high-income parameter estimate does not decline much after we control for parent and primary school teacher views of the child's behaviour and academic abilities (Models 7 and 8) or after inclusion of parental educational expectations for their offspring (Model 9). As in Northern Ireland, around a third of the raw household income gap in grammar school entrance rates in England remains unexplained.

\section{$<<$ Table 7 >>}

\section{Discussion}

Academically selective grammar schools were established in the UK with the aim of creating "an aristocracy of intellect to replace the aristocracy of birth and wealth" (Norwood Report, 1943). However, previous research has shown that family background plays an important role in determining access to grammar schools: just three percent of pupils educated in grammar schools in England are eligible for Free School, despite accounting for 13 percent of the national pupil population (Andrews et al., 2016). Strikingly, lower socio-economic status pupils are less likely to be found in grammar schools than their more advantaged peers, even when they have the same Key Stage 2 test scores (Burgess et al., 2017).

This paper provides new evidence on the strength and drivers of the relationship between parental income and grammar school attendance. Using rich cohort data covering two parts of the UK, we illustrate how family income continues to have a strong association with grammar school attendance. More specifically, we find that pupils from the top quartile of household income are 33\% (Northern Ireland) and 20\% (England) more likely to attend a grammar school than pupils from the bottom quartile, controlling for an extensive set of prior attainment measures. This difference between top and bottom quartile pupils remains even after we control

\footnotetext{
${ }^{8}$ Appendix B suggests that controlling for parental views of their child's behaviour and abilities may be an exception. Specifically, when a multi-nominal logistic regression is estimated, the high-income log-odds (odds ratio) falls from $1.23(\mathrm{OR}=3.42)$ to $0.96(\mathrm{OR}=2.61)$ between models 6 and 7 .
} 
for a very wide range of covariates including school preferences, parental aspirations, parents and teachers views of a child's ability and local area fixed effects.

What explains high-income pupils getting in to grammar school at a higher rate than peers with similar prior academic attainment? In England, we find evidence that private tutoring can explain a large part of this gap. Indeed, we find that the association between being in the top quartile of household income and grammar attendance drops by half once the use of private tutoring is accounted for in our models. This interpretation of the data is also supported by our descriptive findings that private tutoring is used more often in selective education areas, more intensively by more affluent parents, and particularly in the subjects which are assessed in the Eleven Plus entry test. In Northern Ireland, tutoring plays a less important role in explaining grammar attendance gaps, despite being used by a comparable proportion of parents. Although we can only speculate as to the reasons for these differences, it is possible that the replacement of the state-run Eleven Plus in Northern Ireland in 2008 with a number of alternative tests chosen by schools, disrupted the relationship between tutoring and gaining entry to grammar at the time out pupils took their test around 2011.

Consistent with existing research (Burgess et al., 2015; Hastings et al., 2005; Gewirtz et al., 1994; Reay \& Ball, 1997) we find evidence that differences in parental preferences between households in the top and bottom income quartiles can explain a modest amount of the grammar attendance gap. In part, this reflects the strong underlying relationship between household income and preferences for schools with good exam results in Northern Ireland. In England, preference for schools with good exam results do not appear to play a particularly important part in explaining the grammar attendance gap. This reflects a weaker underlying relationship between income and preferences for schools with good results in England. Again, we can only speculate as to the reasons preferences play more of a role in Northern Ireland than in England, but it may be that the alternatives to grammar schools play an important role. In the fully selective system in Northern Ireland, failing to gain entry to grammar schools means attending a school with other low attaining pupils. By contrast, the partially selective system in England means that those who do not gain entry to a grammar school may still attend a school with a comprehensive intake. This may cause a closer alignment between preferences for results and school type in Northern Ireland.

These findings should be interpreted in light of the limitations of this research. First, the MCS sample is somewhat limited in size, particularly in England. Despite the standard errors 
surrounding our estimates being reasonably large, the number of observations is still sufficient to identify variables that account for grammar access gaps. Second, although we have been able to 'explain' (in a statistical sense) a large part of the income-attendance gap, around a third of the raw gap remains unaccounted for in our analysis. There may be other variables which we do not observe in the data - such as covert selection procedures (West \& Hind, 2003) or genetics (Smith-Wooley et al., 2018) - which have an impact upon grammar school entrance rates. Third, our measures of parental preferences, expectations and so on are likely to be subject to a degree of measurement error. In particular, some researchers have criticised the use of lists of factors to measure parental schools preferences, on the grounds that they fail to capture more impressionistic, non-rational considerations (Bowe et al., 1994; Ball \& Vincent, 1998). Despite these imperfections, we believe the richness of our data remains a strength of this research. Fourth, our modelling strategy reveals conditional associations only, and does not necessarily capture cause and effect. Fifth and finally, our results are likely to be influenced by our definition of selective areas. For example, if affluent families select (move) into areas with high grammar school attendance rates, pushing up house prices, then our sample might include fewer families with very low levels of income. This will affect the range of deprivation we observe in our data and, by extension, our estimates. Having said that, we are somewhat reassured by the similarity of the estimates derived from our two different definitions of elective areas.

Despite these limitations, our research has important implications for policy. Critically, our analysis illustrates how access to grammar schools is determined by many factors other than academic attainment. In Northern Ireland parental preferences and private tutoring explain a small but not insignificant part of the grammar attendance gap. In England, private tutoring explains a substantial part of the attendance gap. Grammar schools have therefore fallen well short of their original objective, expressed in the Norwood Report, of breaking the link between educational attainment on the one hand, and birth and wealth on the other. Our findings imply that the government's current policy of expanding existing grammar schools will disproportionately benefit affluent pupils. This is likely to be counterproductive for social mobility. We have shown that large parts of the grammar school attendance gap can be explained by differences in family income and access to private tutoring. Any attempt to equalise access to grammar schools would therefore require either large redistributions of resources in order to enable more disadvantaged pupils to gain access to private tutoring, or the elimination of private tutoring. The present UK government is unlikely to pursue either of these 
reforms, which means their grammar school expansion programme is unlikely to meet its stated objectives. Theresa May and other proponents of selective schools would therefore be better off focusing on increasing the number of places at good comprehensive schools, rather than focusing on grammars.

Finally, our results highlight the importance of private tutoring in determining educational outcomes. Little is currently known about this area (Ireson \& Rushforth, 2011) and future research should probe this further, for example by investigating the contribution made by private tutoring to the results of comprehensive schools in affluent areas.

\section{References}

Allen, R. (2016, August). Grammar schools contaminate comprehensive schooling areas [Blog post]. Retrieved from https://educationdatalab.org.uk/2016/08/grammar-schools-contaminatecomprehensive-schooling-areas/

Andrews, J., Hutchinson, J., \& Johnes, R. (2016). Grammar schools and social mobility. London: Education Policy Institute.

Ball, S. J., Bowe, R., \& Gewirtz, S. (1996). School choice, social class and distinction: the realization of social advantage in education. Journal of Education Policy, 11(1), 89-112.

Ball, S. J., \& Vincent, C. (1998). 'I Heard It on the Grapevine': 'hot' knowledge and school choice. British Journal of Sociology of Education, 19(3), 377-400.

Burgess, S., Greaves, E., Vignoles, A., \& Wilson, D. (2015). What parents want: School preferences and school choice. The Economic Journal, 125(587): 1262-1289.

Blanden, J., Gregg, P., \& Macmillan, L. (2013). Intergenerational persistence in income and social class: the effect of within-group inequality. Journal of the Royal Statistical Society Series A, 176(2), 541-563.

Burgess, S., Dickson, M., \& Macmillan, L. (2014). Do selective schooling systems increase inequality? DQSS Working Paper 14/09, UCL Institute of Education.

Burgess, S., Crawford, C., \& Macmillan, L. (2017). Assessing the role of grammar schools in promoting social mobility. DQSS Working Paper 17/09, UCL Institute of Education.

Francis, B., Archer, L., Hodgen, J., Pepper, D., Taylor, B., \& Travers, M. C. (2017). Exploring the relative lack of impact of research on 'ability grouping' in England: A discourse analytic account. Cambridge Journal of Education, 47(1), 1-17.

Gazeley, L., \& Dunne, M. (2007). Researching class in the classroom: Addressing the social class attainment gap in initial teacher education. Journal of Education for Teaching, 33(4), 409-424.

Gibbons, S., \& Machin, S. (2008). Valuing school quality, better transport, and lower crime: evidence from house prices. Oxford Review of Economic Policy, 24(1), 99-119.

Gewirtz, S., Ball, S. J., \& Bowe, R. (1994). Parents, privilege and the education market-place. Research Papers in Education, 9(1), 3-29. 
Gorard, S. (2015). The uncertain future of comprehensive schooling in England. European Educational Research Journal, 14(3), 257-268.

Hansen, K. (2014). Millennium Cohort Study. A guide to the datasets. London: Centre for Longitudinal Studies, Institute of Education. Accessed 02/11/2017 from http://www.cls.ioe.ac.uk/page.aspx? \&sitesectionid=957\&sitesectiontitle=Surveys+and+docu $\underline{\text { mentation }}$

Hanushek, E., \& Woßmann, L. (2006). Does educational tracking affect performance and inequality? Differences-in-differences evidence across countries. Economic Journal, 116(510), 63-76.

Hastings, J. S., Kane, T. J., \& Staiger, D. O. (2005). Parental preferences and school competition: Evidence from a public school choice program. National Bureau of Economic Research Working Paper No. w11805.

Ireson, J. \& Rushforth, K. (2011). Private tutoring at transition points in the English education system: its nature, extent and purpose. Research Papers in Education, 26(1), 1-19.

Jerrim, J., \& Vignoles, A. (2013). Social mobility, regression to the mean and the cognitive development of high ability children from disadvantaged homes. Journal of the Royal Statistical Society Series A, 176(4), 887-906.

Khattab, N. (2015). Students' aspirations, expectations and school achievement: what really matters? British Educational Research Journal, 41(5), 731-748.

Ketende, S., \& Jones, E. (2011). User Guide to Analysing MCS Data Using Stata. London: Centre for Longitudinal Studies, Institute of Education. Accessed 07/06/2017 from http://www.cls.ioe.ac.uk/library-

media/documents/User\%20Guide\%20to\%20Analysing\%20MCS\%20Data\%20using\%20Stata . $\mathrm{pdf}$

Mood, C. (2010). Logistic regression: why we cannot do what we think we can do, and what we can do about it. European Sociological Review, 26(1), 67-82.

[Norwood Report] (1943) Curriculum and Examinations in Secondary Schools. London: HMSO.

Plewis, I. (2004). Millennium Cohort Study First Survey: Technical Report on Sampling. London: Centre for Longitudinal Studies, Institute of Education. Accessed 16/06/2017 from file:///C:/Users/john/Downloads/MCS1_Technical_Report_on_Sampling_June_2004\%20(3). pdf

Reay, D., \& Ball, S. J. (1997). Spoilt for choice': the working classes and educational markets. Oxford Review of Education, 23(1), 89-101.

Reay, D., \& Ball, S. J. (1998). 'Making their Minds Up': family dynamics of school choice. British Educational Research Journal, 24(4), 431-448.

Reay, D. (2004). Exclusivity, exclusion, and social class in urban education markets in the United Kingdom. Urban education, 39(5), 537-560.

Schoon, I., \& Parsons, S. (2002). Teenage aspirations for future careers and occupational outcomes. Journal of Vocational Behavior, 60(2), 262-288. 
Secondary Education and Social Change [SESC] (2018) Briefing Paper: Grammar Schools. Cambridge: University of Cambridge. Accessed 06/09/2018 https://sesc.hist.cam.ac.uk/wpcontent/uploads/2018/01/Briefing-paper-Grammar-Schools.pdf

Smith-Woolley, E., Pingault, J. B., Selzam, S., Rimfeld, K., Krapohl, E., von Stumm, S., ... \& Kovas, Y. (2018). Differences in exam performance between pupils attending selective and non-selective schools mirror the genetic differences between them. npj Science of Learning, 3(1), 3.

Sutton Trust. 2013. 'Poor grammar. Entry into grammar schools disadvantaged pupils in England'. Accessed 06/06/2017 from https://www.suttontrust.com/researcharchive/poorgrammar-entry-grammar-schools-disadvantaged-pupils-england/

West, A., \& Hind, A. (2003). Secondary school admissions in England: Exploring the extent of overt and covert selection. London: Rise Trust. 
Table 1. The association between family income and grammar school entrance rates in Northern Ireland

\begin{tabular}{|c|c|c|c|c|c|c|c|c|c|c|c|c|c|c|c|c|c|c|}
\hline & \multicolumn{2}{|c|}{ Model 1} & \multicolumn{2}{|c|}{ Model 2} & \multicolumn{2}{|c|}{ Model 3} & \multicolumn{2}{|c|}{ Model 4} & \multicolumn{2}{|c|}{ Model 5} & \multicolumn{2}{|c|}{ Model 6} & \multicolumn{2}{|c|}{ Model 7} & \multicolumn{2}{|c|}{ Model 8} & \multicolumn{2}{|c|}{ Model 9} \\
\hline & Beta & SE & Beta & SE & Beta & SE & Beta & SE & Beta & SE & Beta & SE & Beta & SE & Beta & SE & Beta & SE \\
\hline \multicolumn{19}{|l|}{ Household income } \\
\hline Bottom quartile (Reference) & - & - & - & - & - & - & - & - & - & - & - & - & - & - & - & - & - & - \\
\hline Second quartile & $11.1 \%$ & $4.9 \%$ & $6.4 \%$ & $4.4 \%$ & $6.8 \%$ & $4.4 \%$ & $6.6 \%$ & $4.4 \%$ & $4.6 \%$ & $4.3 \%$ & $4.7 \%$ & $4.3 \%$ & $3.7 \%$ & $4.6 \%$ & $-1.0 \%$ & $4.3 \%$ & $-0.5 \%$ & $4.2 \%$ \\
\hline Third quartile & $30.6 \%$ & $5.5 \%$ & $18.4 \%$ & $5.1 \%$ & $15.3 \%$ & $4.7 \%$ & $13.6 \%$ & $4.6 \%$ & $10.4 \%$ & $4.8 \%$ & $10.5 \%$ & $4.7 \%$ & $10.0 \%$ & $4.8 \%$ & $\underline{8.0 \%}$ & $4.7 \%$ & $8.6 \%$ & $4.7 \%$ \\
\hline Top quartile & $52.9 \%$ & $0.5 \%$ & $33.2 \%$ & $4.7 \%$ & $25.0 \%$ & $4.9 \%$ & $21.7 \%$ & $5.0 \%$ & $17.7 \%$ & $4.8 \%$ & $18.2 \%$ & $4.7 \%$ & $16.9 \%$ & $4.9 \%$ & $\overline{14.5 \%}$ & $4.9 \%$ & $\overline{15.3 \%}$ & $4.9 \%$ \\
\hline \multicolumn{19}{|l|}{ Controls } \\
\hline Gender & \multicolumn{2}{|c|}{ Yes } & \multicolumn{2}{|c|}{ Yes } & \multicolumn{2}{|c|}{ Yes } & \multicolumn{2}{|c|}{ Yes } & \multicolumn{2}{|c|}{ Yes } & \multicolumn{2}{|c|}{ Yes } & \multicolumn{2}{|c|}{ Yes } & \multicolumn{2}{|c|}{ Yes } & \multicolumn{2}{|c|}{ Yes } \\
\hline Parent religion & \multicolumn{2}{|c|}{ Yes } & \multicolumn{2}{|c|}{ Yes } & \multicolumn{2}{|c|}{ Yes } & \multicolumn{2}{|c|}{ Yes } & \multicolumn{2}{|c|}{ Yes } & \multicolumn{2}{|c|}{ Yes } & \multicolumn{2}{|c|}{ Yes } & \multicolumn{2}{|c|}{ Yes } & \multicolumn{2}{|c|}{ Yes } \\
\hline Prior attainment & - & & Y & & $\mathrm{Y}$ & & $Y$ & & $\mathrm{Ye}$ & & $\mathrm{Y}$ & & & & $\mathrm{Y}$ & & $\mathrm{Y}$ & \\
\hline Election ward fixed effects & - & & & & $\mathrm{Y}$ & & $\mathrm{Y}$ & & $\mathrm{Ye}$ & & $\mathrm{Y}$ & & Y & & $\mathrm{Y}$ & & Y & \\
\hline Private tutoring/coaching & - & & & & - & & $\mathrm{Y}$ & & $\mathrm{Ye}$ & & $\mathrm{Y}$ & & & & $\mathrm{Y}$ & & Y & \\
\hline School choice: results important & - & & & & - & & - & & $Y$ & & $\mathrm{Y}$ & & & & $\mathrm{Y}$ & & Y & \\
\hline School choice: full controls & - & & & & - & & - & & - & & $\mathrm{Y}$ & & & & $\mathrm{Y}$ & & Y & \\
\hline Parent views on child's ability & - & & & & - & & - & & - & & - & & & & $\mathrm{Y}$ & & & \\
\hline Parent views of non-cog skills & - & & & & - & & - & & - & & . & & & & $\mathrm{Y}$ & & Y & \\
\hline Teacher's views on child's ability & - & & & & - & & - & & - & & r & & & & $\mathrm{Y}$ & & Y & \\
\hline Teacher's views of non-cog skills & - & & & & - & & - & & - & & . & & & & $\mathrm{Y}$ & & Y & \\
\hline Parental expectations age 7 & - & & the & & - & & - & & - & & - & & - & & - & & $\mathrm{Y}$ & \\
\hline & $\mathbf{1 , 0}$ & & $\mathbf{1 , 0}$ & & $\mathbf{1 , 0}$ & & 1,0 & & $\mathbf{1 , 0}$ & & $\mathbf{1 , 0}$ & & $\mathbf{1 ,}$ & & 1,0 & & $\overline{1,0}$ & \\
\hline
\end{tabular}

Authors' estimates using the MCS data. Bold font indicates statistical significance at the five percent level, and underlined italic font at the ten percent level. Estimates based upon a linear probability model. Estimates refer to the percentage point increase in the probability of entering to a grammar school. 46 percent of the sample attended a grammar school. 
Table 2. The relationship between family income and parental actions to boost their children's chances of gaining entry to grammar school in Northern Ireland

(a) Relationship between family income and actions parents take to get their child into their chosen school

\begin{tabular}{|l|cc|}
\hline Action taken & $\begin{array}{c}\text { \% point change per } \\
\mathbf{1 1 0 0} \text { increase in } \\
\text { weekly income }\end{array}$ & $\begin{array}{c}\text { Standard } \\
\text { error }\end{array}$ \\
\hline Taken entrance exam & $6.9 \% * *$ & $0.9 \%$ \\
Extra lessons in Maths & $6.7 \% * *$ & $1.0 \%$ \\
Extra lessons in English & $6.6 \% * *$ & $0.9 \%$ \\
Arranged tuition / coaching & $6.0 \% * *$ & $1.0 \%$ \\
Other steps & $3.1 \% * *$ & $1.2 \%$ \\
Attend after school club & $-2.2 \% * *$ & $0.8 \%$ \\
Help with homework & $-2.0 \% * *$ & $1.0 \%$ \\
Extra lessons in science & $0.1 \%$ & $0.2 \%$ \\
\hline
\end{tabular}

(b) Relationship between coaching and grammar school entrance

\begin{tabular}{lcc}
\hline & \multicolumn{2}{c}{ Northern Ireland } \\
Attend grammar & Not coached & Coached \\
\hline No & $59 \%(476)$ & $22 \%(33)$ \\
Yes & $41 \%(334)$ & $78 \%(114)$ \\
\hline
\end{tabular}

Notes: All questions in panel (a) are binary (yes/no), with estimates referring to results from a linear probability model where only demographic characteristics have been controlled. ** indicates statistical significance at the five percent level. In panel (b), the number of observations are reported in parentheses, with figures based upon unweighted data 
Table 3. The relationship between family income and parental school preferences in Northern Ireland

\begin{tabular}{lcc}
\hline Reason for choosing school & $\begin{array}{c}\text { \% point change per } \\
\mathbf{1 0 0} \text { increase in } \\
\text { weekly income }\end{array}$ & $\begin{array}{c}\text { Standard } \\
\text { error }\end{array}$ \\
\hline Good exam results / reputation & $9.0 \% \%^{* *}$ & $0.8 \%$ \\
Good range of extra-curricular activities & $5.7 \% \%^{* *}$ & $0.9 \%$ \\
Has good facilities & $5.3 \% \%^{* *}$ & $0.9 \%$ \\
General good impression of school & $5.0 \% * *$ & $0.9 \%$ \\
Religious grounds & $2.8 \% * *$ & $1.0 \%$ \\
Child wanted to go there & $2.6 \% * *$ & $0.8 \%$ \\
Friends intending to go there & $2.0 \% *$ & $1.0 \%$ \\
Nearest school to home & $1.4 \%$ & $1.1 \%$ \\
Has a specialist curriculum & $1.1 \%$ & $0.6 \%$ \\
Strong anti-bullying policy & $0.6 \%$ & $0.9 \%$ \\
Other relative went there & $0.3 \%$ & $0.8 \%$ \\
Other & $0.1 \%$ & $0.1 \%$ \\
Don't know & $0.0 \%$ & $0.0 \%$ \\
Brother/sister goes there & $-1.0 \%$ & $0.9 \%$ \\
\hline
\end{tabular}

Notes: All variables are binary responses (yes/no). * and ** indicate statistical significance at the ten and five percent significant thresholds respectively. 
Table 4. The association between family income and grammar school entrance rates in England

\begin{tabular}{|c|c|c|c|c|c|c|c|c|c|c|c|c|c|c|c|c|c|c|}
\hline & \multicolumn{2}{|c|}{ Model 1} & \multicolumn{2}{|c|}{ Model 2} & \multicolumn{2}{|c|}{ Model 3} & \multicolumn{2}{|c|}{ Model 4} & \multicolumn{2}{|c|}{ Model 5} & \multicolumn{2}{|c|}{ Model 6} & \multicolumn{2}{|c|}{ Model 7} & \multicolumn{2}{|c|}{ Model 8} & \multicolumn{2}{|c|}{ Model 9} \\
\hline & Beta & SE & Beta & SE & Beta & SE & Beta & SE & Beta & SE & Beta & SE & Beta & SE & Beta & SE & Beta & SE \\
\hline \multicolumn{19}{|l|}{ Household income } \\
\hline Bottom quartile (Reference) & - & - & - & - & - & - & - & - & - & - & - & - & - & - & - & - & - & - \\
\hline Second quartile & $14.1 \%$ & $4.7 \%$ & $9.1 \%$ & $4.5 \%$ & $8.8 \%$ & $4.3 \%$ & $7.2 \%$ & $4.0 \%$ & $8.3 \%$ & $4.1 \%$ & $8.2 \%$ & $4.3 \%$ & $7.8 \%$ & $4.3 \%$ & $8.2 \%$ & $4.4 \%$ & $8.3 \%$ & $4.4 \%$ \\
\hline Third quartile & $20.2 \%$ & $4.4 \%$ & $12.1 \%$ & $4.6 \%$ & $12.6 \%$ & $4.8 \%$ & $6.0 \%$ & $3.9 \%$ & $6.5 \%$ & $3.9 \%$ & $5.8 \%$ & $3.9 \%$ & $6.6 \%$ & $4.2 \%$ & $6.3 \%$ & $4.4 \%$ & $6.3 \%$ & $4.4 \%$ \\
\hline Top quartile & $35.7 \%$ & $3.7 \%$ & $21.0 \%$ & $3.8 \%$ & $23.6 \%$ & $4.5 \%$ & $12.9 \%$ & $3.9 \%$ & $13.4 \%$ & $3.8 \%$ & $12.0 \%$ & $4.0 \%$ & $12.4 \%$ & $4.1 \%$ & $11.7 \%$ & $4.2 \%$ & $12.0 \%$ & $4.2 \%$ \\
\hline \multicolumn{19}{|l|}{ Controls } \\
\hline Gender & \multicolumn{2}{|c|}{ Yes } & \multicolumn{2}{|c|}{ Yes } & \multicolumn{2}{|c|}{ Yes } & \multicolumn{2}{|c|}{ Yes } & \multicolumn{2}{|c|}{ Yes } & \multicolumn{2}{|c|}{ Yes } & \multicolumn{2}{|c|}{ Yes } & \multicolumn{2}{|c|}{ Yes } & \multicolumn{2}{|c|}{ Yes } \\
\hline Prior attainment & \multicolumn{2}{|c|}{-} & \multicolumn{2}{|c|}{ Yes } & \multicolumn{2}{|c|}{ Yes } & \multicolumn{2}{|c|}{ Yes } & \multicolumn{2}{|c|}{ Yes } & \multicolumn{2}{|c|}{ Yes } & \multicolumn{2}{|c|}{ Yes } & \multicolumn{2}{|c|}{ Yes } & \multirow{2}{*}{\multicolumn{2}{|c|}{$\begin{array}{l}\text { Yes } \\
\text { Yes }\end{array}$}} \\
\hline LEA fixed effects & \multirow{2}{*}{\multicolumn{2}{|c|}{-}} & - & & $\mathrm{Ye}$ & & Yes & & $\mathrm{Y}$ & & Ye & & $\mathrm{Ye}$ & & $\mathrm{Ye}$ & & & \\
\hline Private tutoring/coaching & & & - & & - & & Yes & & $\mathrm{Y}$ & & $\mathrm{Ye}$ & & $\mathrm{Ye}$ & & $\mathrm{Ye}$ & & $\mathrm{Y}$ & \\
\hline School choice: results important & - & & - & & - & & - & & $\mathrm{Y}$ & & Ye & & $\mathrm{Ye}$ & & $\mathrm{Ye}$ & & $\mathrm{Y}$ & \\
\hline School choice: full controls & - & & - & & - & & - & & & & $\mathrm{Ye}$ & & $\mathrm{Ye}$ & & $\mathrm{Ye}$ & & $\mathrm{Y}$ & \\
\hline Parent views on child's ability & - & & - & & - & & - & & & & - & & $\mathrm{Ye}$ & & $\mathrm{Ye}$ & & $\mathrm{Y}$ & \\
\hline Parent views of non-cog skills & - & & - & & - & & - & & & & - & & $\mathrm{Ye}$ & & $\mathrm{Ye}$ & & $\mathrm{Y}$ & \\
\hline Teacher's views on child's ability & - & & - & & - & & - & & & & - & & - & & $\mathrm{Ye}$ & & $\mathrm{Y}$ & \\
\hline Teacher's views of non-cog skills & - & & 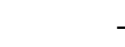 & & - & & - & & & & - & & - & & $\mathrm{Ye}$ & & $\mathrm{Y}$ & \\
\hline Parental expectations age 7 & - & & - & & - & & - & & & & - & & - & & - & & $\mathrm{Y}$ & \\
\hline & 81 & & 81 & & 81 & & 819 & & 8 & & 81 & & 80 & & 80 & & 80 & \\
\hline
\end{tabular}

Authors' estimates using the MCS data. Bold font indicates statistical significance at the five percent level, and underlined italic font at the ten percent level. Estimates based upon a linear probability model. Estimates refer to the percentage point increase in the probability of entering a grammar or private school. 24 percent of the sample attended a grammar school and six percent a private school. The remaining 70 percent attend a non-grammar state school. 
Table 5. The relationship between family income and parental actions to boost their children's chances of gaining entry to grammar school

(a) Relationship between family income and actions parents take to get their child into their chosen school

\begin{tabular}{l|cc|cc}
\hline & \multicolumn{2}{|c|}{ Selective } & \multicolumn{2}{c}{ Comprehensive } \\
\hline Action taken & $\begin{array}{c}\text { \% point change per } \\
£ 100 \text { increase in } \\
\text { weekly income }\end{array}$ & $\begin{array}{c}\text { Standard } \\
\text { error }\end{array}$ & $\begin{array}{c}\text { \% point change per } \\
\text { 1100 increase in } \\
\text { weekly income }\end{array}$ & $\begin{array}{c}\text { Standard } \\
\text { error }\end{array}$ \\
\hline Extra lessons in English & $3.7 \% * *$ & $0.6 \%$ & $1.7 \% * *$ & $0.4 \%$ \\
Extra lessons in Maths & $4.8 \% * *$ & $0.8 \%$ & $1.7 \% * *$ & $0.4 \%$ \\
Arranged tuition / coaching & $5.9 \% * *$ & $0.7 \%$ & $1.5 \% * *$ & $0.3 \%$ \\
Other steps & $0.0 \%$ & $0.3 \%$ & $-0.1 \%$ & $0.2 \%$ \\
Taken entrance exam & $6.2 \% * *$ & $1.1 \%$ & $3.6 \% * *$ & $0.4 \%$ \\
Help with homework & $-1.9 \% * *$ & $0.7 \%$ & $0.2 \%$ & $0.5 \%$ \\
Extra lessons in science & $0.1 \%$ & $0.3 \%$ & $0.1 \%$ & $0.1 \%$ \\
Attend after school club & $-1.1 \%$ & $0.8 \%$ & $1.1 \% * *$ & $0.3 \%$ \\
\hline
\end{tabular}

(b) Relationship between coaching and grammar school entrance

\begin{tabular}{lcc}
\hline & \multicolumn{2}{c}{ England } \\
Attend grammar & Not coached & Coached \\
\hline No & $86 \%(567)$ & $27 \%(42)$ \\
Yes & $14 \%(94)$ & $73 \%(116)$ \\
\hline
\end{tabular}

Notes: The number of observations are included in parentheses. Unweighted data. Pupils who go on to attend private school at age 14 excluded from panel (b). 
Table 6. The link between family income, prior achievement and the probability of receiving coaching/private tuition in England

\begin{tabular}{lccc}
\hline & Coaching & $\begin{array}{c}\text { Tutoring } \\
\text { maths }\end{array}$ & $\begin{array}{c}\text { Tutoring } \\
\text { English }\end{array}$ \\
\hline Family income quartile & & & \\
Bottom quartile & $<5 \%$ & $16 \%$ & $15 \%$ \\
Q2 & $9 \%$ & $16 \%$ & $10 \%$ \\
Q3 & $16 \%$ & $22 \%$ & $18 \%$ \\
Top quartile & $29 \%$ & $34 \%$ & $28 \%$ \\
Prior achievement maths (age 7) & & & \\
Bottom quartile & $7 \%$ & $29 \%$ & $24 \%$ \\
Q2 & $16 \%$ & $27 \%$ & $23 \%$ \\
Q3 & $24 \%$ & $24 \%$ & $15 \%$ \\
Top quartile & $28 \%$ & $22 \%$ & $20 \%$ \\
Prior achievement reading (age 7) & & & \\
Bottom quartile & $<5 \%$ & $25 \%$ & $26 \%$ \\
Q2 & $17 \%$ & $20 \%$ & $19 \%$ \\
Q3 & $26 \%$ & $33 \%$ & $23 \%$ \\
Top quartile & $29 \%$ & $26 \%$ & $16 \%$ \\
\hline
\end{tabular}


Table 7. The relationship between family income and parental school preferences in England

\begin{tabular}{lcc|cc}
\hline & \multicolumn{2}{c|}{ Selective } & \multicolumn{2}{c}{ Comprehensive } \\
\hline Reason for choosing school & $\begin{array}{c}\text { \% point change } \\
\text { per £100 increase } \\
\text { in weekly income }\end{array}$ & SE & $\begin{array}{c}\text { \% point change } \\
\text { per £100 increase } \\
\text { in weekly income }\end{array}$ & SE \\
\hline Good exam results / reputation & $\mathbf{4 . 4 \%} * *$ & $0.8 \%$ & $\mathbf{6 . 4 \%} \% *$ & $0.5 \%$ \\
General good impression of school & $\mathbf{4 . 4 \%} * *$ & $0.8 \%$ & $\mathbf{5 . 1 \%} * *$ & $0.4 \%$ \\
Good range of extra-curricular activities & $1.0 \%$ & $0.9 \%$ & $\mathbf{4 . 7 \%} \% *$ & $0.5 \%$ \\
Religious grounds & $1.0 \%$ & $0.5 \%$ & $0.8 \% *$ & $0.5 \%$ \\
Child wanted to go there & $0.8 \%$ & $0.7 \%$ & $\mathbf{1 . 9 \%} * *$ & $0.5 \%$ \\
Strong anti-bullying policy & $0.6 \%$ & $0.8 \%$ & $\mathbf{1 . 1 \%} \% *$ & $0.5 \%$ \\
Has good facilities & $0.2 \%$ & $0.9 \%$ & $\mathbf{4 . 3 \%} \% *$ & $0.4 \%$ \\
Other & $0.0 \%$ & $0.1 \%$ & $0 \%$ & $0.1 \%$ \\
Nearest school to home & $-0.5 \%$ & $0.9 \%$ & $-0.8 \%$ & $0.6 \%$ \\
Has a specialist curriculum & $-0.9 \%$ & $0.6 \%$ & $0.4 \%$ & $0.4 \%$ \\
Other relative went there & $-1.1 \%$ & $0.4 \%$ & $\mathbf{- 1 . 6 \%} \% *$ & $0.3 \%$ \\
Friends intending to go there & $-1.2 \%$ & $0.8 \%$ & $\mathbf{1 . 0 \%} \% *$ & $0.3 \%$ \\
Brother/sister goes there & $-1.3 \%$ & $0.8 \%$ & $\mathbf{- 1 . 6 \% * *}$ & $0.5 \%$ \\
\hline
\end{tabular}

Notes: * and ** indicate statistical significance at the ten and five percent significant thresholds respectively. 
Figure 1. The local of grammar schools in England and where their pupils live

(a) Location of grammar schools

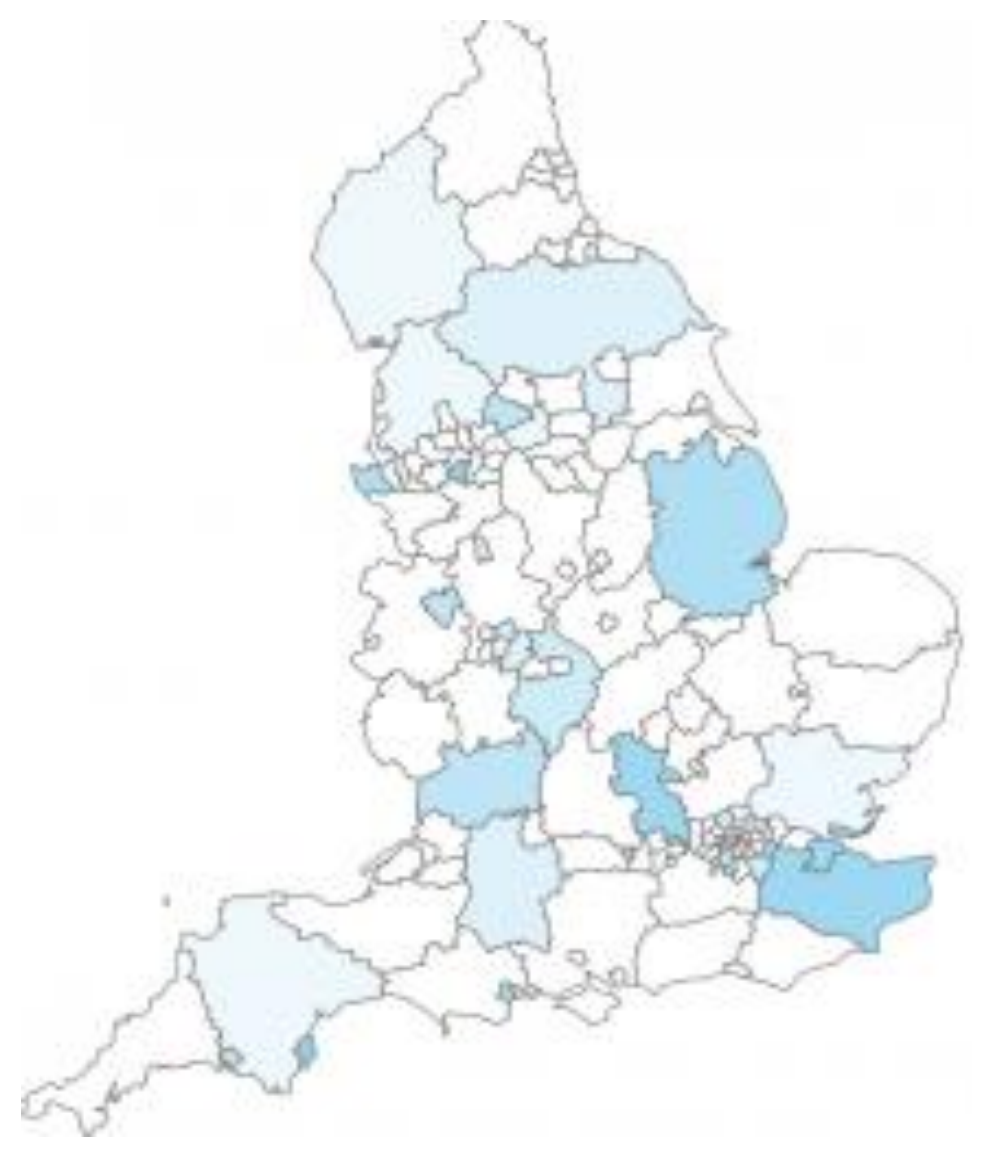

(b) Where grammar school pupils live

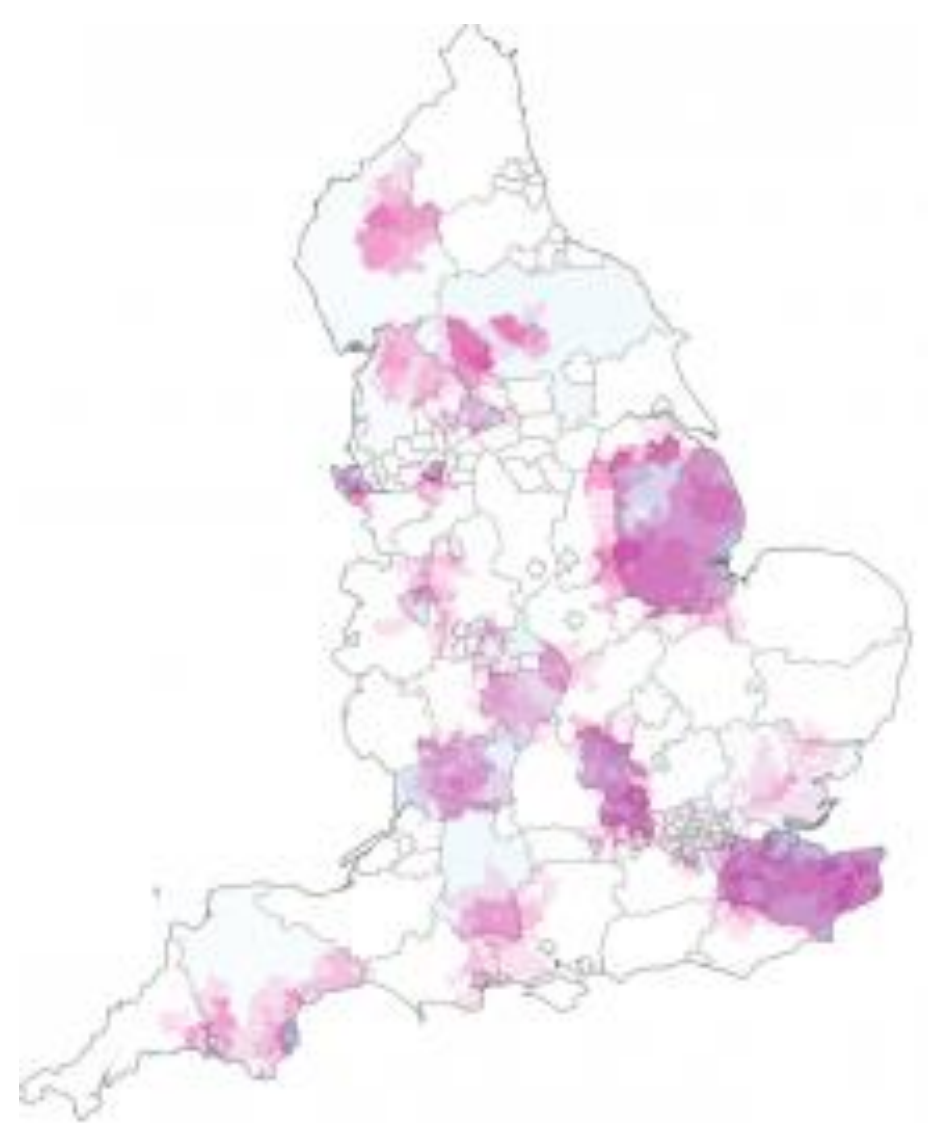

Source: Allen (2016).Notes: Darker shading refers to a greater concentration of grammar schools (panel a) or proportion of pupils who attend a grammar school. 
Figure 2. The relationship between permanent family income and the probability of attending a grammar school

(a) Northern Ireland

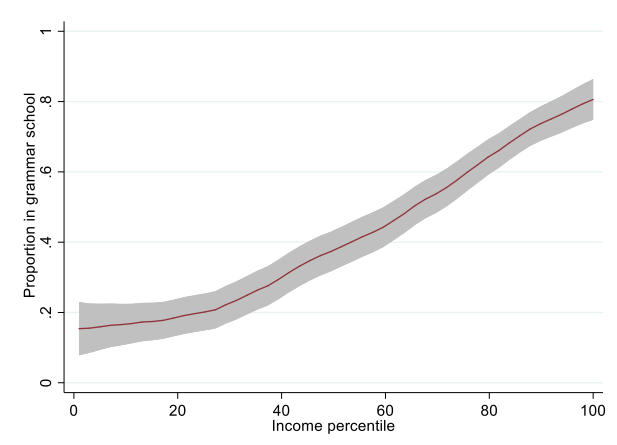

(b) England

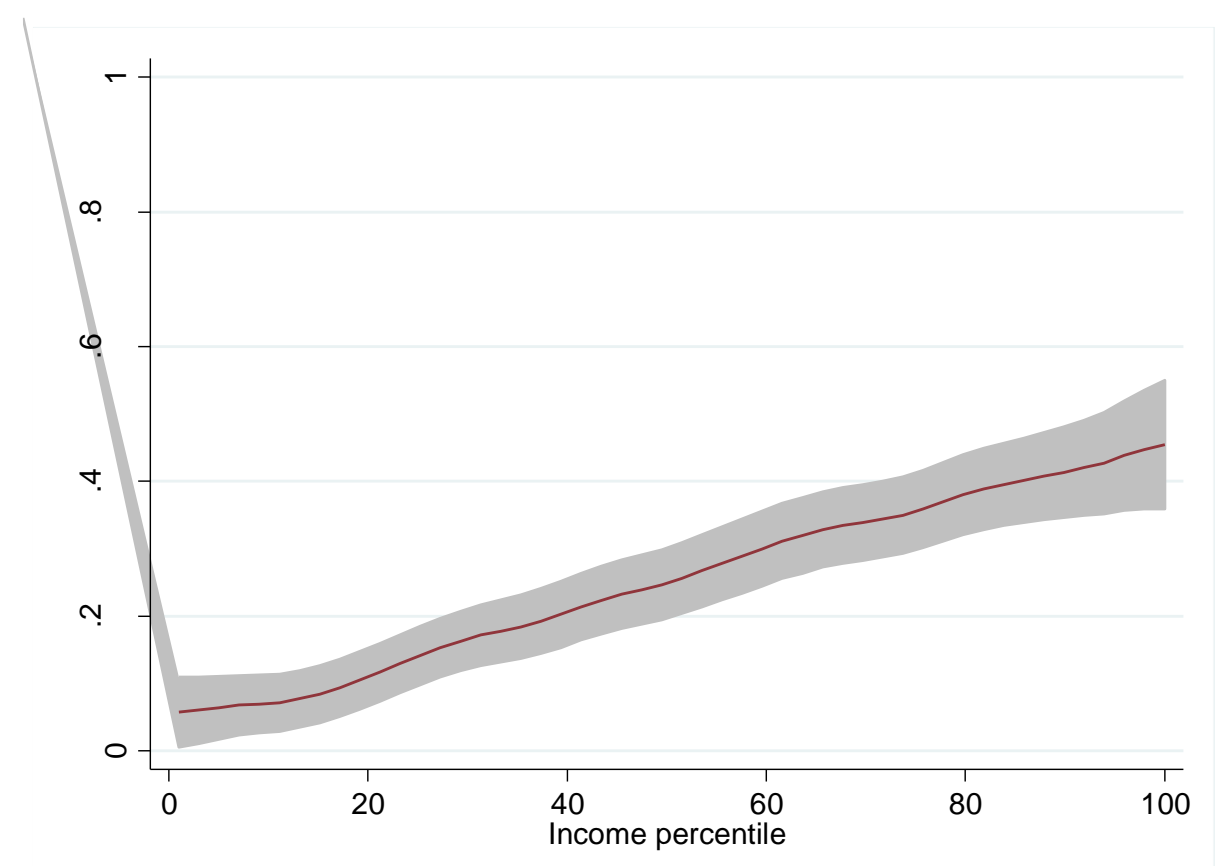

Notes: Authors' calculations using the MCS data. Graph illustrates how the probability of attending a grammar school increases with equivalised weekly family income. 